\title{
Dinâmica do conteúdo de monossacarídeos em gemas e ramos de dois anos de macieira durante a endodormência
}

\author{
Dynamics of monosaccharides content in two year old buds and stems of apple tree during \\ the dormancy period
}

\author{
Ruy Inacio Neiva de Carvalho ${ }^{1}$ Flávio Zanette $^{2}$
}

\section{RESUMO}

O objetivo do trabalho foi determinar as variações do conteúdo de glucose, frutose e sorbitol em gemas e ramos de dois anos de macieira que receberam ou não frio suplementar durante o período de dormência. Os ramos da cultivar Imperial Gala foram coletados em Porto Amazonas-PR, região de baixa ocorrência de frio, em intervalos de 21 dias, de abril a agosto, e receberam ou não tratamento com frio suplementar de 1.440 horas, à temperatura de 4 a $7^{\circ} \mathrm{C}$. As análises dos monossacarídeos foram realizadas em gemas e porções de ramos adjacentes a elas por cromatografia líquida de alta eficiência (HPLC). Houve acúmulo de glucose e frutose em gemas de macieira de abril a agosto, e este aumento foi estimulado pelo tratamento com 1.440 horas de frio. O conteúdo de glucose e frutose nos ramos adjacentes às gemas elevou-se de abril ao início de agosto, com posterior queda no final de agosto e o tratamento com frio antecipou esta dinâmica. $O$ conteúdo de sorbitol em gemas e ramos de macieira oscilou de abril a agosto, e sua dinâmica foi alterada pelo frio.

Palavras-chave: Malus domestica Borkh., “Imperial Gala”, fisiologia, glucose, frutose, sorbitol.

\section{ABSTRACT}

The objective of this work was to evaluate the variation of glucose, fructose and sorbitol content in two year old buds and stems of apple trees during the dormancy period. Stems of cv. Imperial Gala were collected in Porto Amazonas, Parana State, Brazil, a region of low chill occurence, at intervals of 21 days from April to August and were treated or not with 1,440 hours of chill ( 4 to $7^{\circ} \mathrm{C}$ ). The monosaccharides were analysed in buds and stem tissues close to buds by high performance liquid chromatography (HPLC). There was an increase of glucose and fructose content in buds from April to August and it was stimulated by the chill treatment. The glucose and fructose content in stems increased from April to August $2^{\text {nd }}$ followed by a reduction in August $23^{\text {rd }}$ and the chill treatment advanced this dynamics. The sorbitol content in buds and stems of apple tree oscillated from April to August and its dynamics was modified by the chill treatment.

Key words: Malus domestica Borkh., 'Imperial Gala', physiology, glucose, fructose, sorbitol.

\section{INTRODUÇÃO}

A dormência de gemas pode se estender ao longo do ano, passando pelas fases de ecodormência, paradormência e endodormência. Na ecodormência, o desenvolvimento da gema não acontece devido a um fator ambiental, e um novo fluxo de crescimento ocorre quando as condições ideais são estabelecidas. $\mathrm{Na}$ paradormência, a ausência de desenvolvimento da gema é resultante de sua inibição por outro órgão ou região do vegetal em crescimento, como as gemas terminais (LANG et al., 1987). É, por isso, conhecida como inibição à longa distância.

A endodormência ocorre nos meses mais frios, em que o não desenvolvimento da gema é resultante de uma série de eventos bioquímicos e fisiológicos que acontecem em níveis meristemáticos ou muito próximos. Nesta etapa, as gemas desenvolvem uma fisiologia especial para proteção contra baixas temperaturas, garantindo a brotação e o florescimento na primavera seguinte (CRABBÉ \& BARNOLA, 1996; LANG et al., 1987). Em um sistema produtivo, a endodormência é a fase mais preocupante para os

${ }^{1}$ Centro de Ciências Agrárias e Ambientais da Pontifícia Universidade Católica do Paraná (PUC), Rodovia BR 376, Km 14, 83010500, São José dos Pinhais, PR, Brasil. Fone: (41) 3299-4300. E-mail: ruy.carvalho@pucpr.br. Autor para correspodência.

${ }^{2}$ Departamento de Fitotecnia e Fitossanitarismo da Universidade Federal do Paraná (UFPR). Rua dos Funcionários, 1540, 80035050, Curitiba, PR, Brasil. Fone: (41) 3350-5650. E-mail: flazan@ufpr.br 
produtores, uma vez que a má brotação ou a brotação desuniforme podem comprometer a produção futura e a condução da planta.

Durante a endodormência de gemas, as atividades metabólicas essenciais continuam a ocorrer, embora com intensidade reduzida (PETRI et al., 1996). Diversas causas podem estar envolvidas com a endodormência, como modificações na estrutura celular (LARCHER, 2000), conteúdo e fluxo de carboidratos à curta distância e suprimento de nutrientes (CARVALHO, 2001; EREZ, 2000; MARQUAT et al., 1999). A baixa atividade metabólica nesta etapa permite alterações nos conteúdos de carboidratos nas gemas ou em suas adjacências, cuja dinâmica pode inibir ou favorecer o crescimento de um novo órgão na planta. Variações do conteúdo de carboidratos totais durante a endodormência já foram identificadas em gemas de macieira (CARVALHO \& ZANETTE, 2004a) e de pessegueiro (LEITE et al., 2004). Porém, é importante a análise isolada de monossacarídeos, pois seu metabolismo diferenciado pode gerar respostas fisiológicas distintas (CARVALHO, 2001).

A sacarose é a mais importante forma de transporte de carbono em plantas (QUICK \& SCHAFFER, 1996), mas, na família Rosaceae o sorbitol é freqüentemente o principal produto fotossintético (LOESCHER \& EVERARD, 1996; SALISBURY \& ROSS, 1992). O sorbitol exerce funções em tecidos não fotossintetizantes como as de armazenamento, transporte, tolerância à desidratação e resistência ao congelamento, em virtude de sua capacidade de regulação osmótica e de proteção de enzimas (LOESCHER \& EVERARD, 1996).

No pessegueiro, o sorbitol é o carboidrato solúvel mais comum durante a quebra de dormência, enquanto a sacarose predomina durante a dormência (FLORE \& LAYNE, 1996). Em pereiras, o sorbitol é o carboidrato mais abundante de translocação, seguido da glucose, da frutose e da sacarose, e suas variações podem ser usadas para indicar o término da endodormência, baseado na translocação de carboidratos para as gemas (HERTER et al., 2001). Em pereiras, o conteúdo de sorbitol nas gemas foi alterado pela flutuação térmica, enquanto o conteúdo de glucose e frutose não se modificou (HERTER et al., 2002).

Essas variações do conteúdo de carboidratos podem ser alteradas de acordo com a idade das gemas avaliadas, pois há diferenças morfológicas entre elas que sugerem alterações fisiológicas. Gemas de macieira com dois anos de idade apresentam primórdio caulinar em seu interior, perfeitamente ligado ao ramo no qual estão inseridas (CARVALHO \& ZANETTE, 2005).
Gemas de dois anos são importantes no momento da formação da copa ou para renovação de estruturas produtivas de macieiras. Assim, o estudo da fisiologia da dormência destas gemas e sua alteração pelas baixas temperaturas gera importantes subsídios para a compreensão do fenômeno e para o planejamento de estudos futuros (CARVALHO \& ZANETTE, 2004b).

O objetivo do trabalho foi determinar as variações do conteúdo de glucose, frutose e sorbitol em gemas e ramos de dois anos de macieira que receberam ou não frio suplementar, durante o período de dormência, como um indicativo de saída da endodormência e do desenvolvimento de capacidade de brotação e geração de um novo ciclo de crescimento.

\section{MATERIAL E MÉTODOS}

Ramos de dois anos com gemas dormentes de macieira da cultivar "Imperial Gala” foram coletados no período de abril a agosto de 2000, em pomar com cinco anos de idade, conduzido em plantio adensado (4,0 x 1,35m) na Fazenda Agropecuária Boutin, em Porto Amazonas - PR $\left(25,55^{\circ}\right.$ de latitude Sul, 49,90 de longitude Oeste e $795 \mathrm{~m}$ de altitude). A quantificação do frio ocorrido na região foi determinada segundo o método do número de horas de frio (HF) abaixo de $7,2^{\circ} \mathrm{C}$ e pelo método da conversão de temperaturas para unidades de frio (UF), baseado no modelo Carolina do Norte (SHALTOUT \& UNRATH, 1983). No ano de 1999, ano de formação das gemas, ocorreram 276 HF ou 362 UF e, no ano de 2000, ocorreram 386 HF e 211,5 UF na região, considerada de baixa ocorrência de frio.

Os ramos íntegros com disposição espacial oblíqua foram coletados em sete datas distintas (19/04, 10/05, 31/05, 21/06, 12/07, 02/08 e 23/08). Em seguida, receberam ou não tratamento com frio suplementar de 1.440 horas à temperatura de 4 a $7^{\circ} \mathrm{C}$ em geladeira, tempo superior aos níveis mínimos requeridos pela macieira “Gala”, a qual originou a "Imperial Gala”, que exige até 600 horas de frio para superação da dormência (PETRI et al., 1996).

As gemas laterais foram coletadas por meio de um corte longitudinal entre a gema e o ramo e de outro transversal no ponto de sua inserção no ramo, retirando-se as cinco escamas (catáfilos) mais externas. As amostras de ramos foram obtidas por meio do fracionamento de porções de ramos com $1,0 \mathrm{~cm}$ de comprimento, divididos ao meio longitudinalmente, mantendo-se para análise a metade que possuía no centro uma gema que foi eliminada. As amostras de gemas (dois frascos Eppendorf de 1,5mL) e ramos (15g envolvidos em filmes plásticos de PVC) foram imediatamente armazenadas a $-18^{\circ} \mathrm{C}$. 
As extrações e determinações do conteúdo de glucose, frutose e sorbitol foram realizadas no Laboratório de Carboidratos de Exsudatos Vegetais do Departamento de Bioquímica e no Laboratório de Cromatografia e Espectrofotometria do Departamento de Química da Universidade Federal do Paraná.

Foi realizada a secagem de gemas e ramos em estufa a $70^{\circ} \mathrm{C}$ até massa constante, seguida de moagem em moinho tipo Willey TE - 650 para ramos, ou em cápsula com bastão de porcelana para gemas. A extração etanólica foi realizada tratando-se $100 \mathrm{mg}$ de amostra seca com $30 \mathrm{~mL}$ de etanol $80 \%$ por 30 minutos a $100^{\circ} \mathrm{C}$, em banho-maria (GAUDILLÈRE et al., 1992). Após a extração, obteve-se por filtração a fração solúvel em álcool (FSA). O volume do filtrado etanólico foi concentrado sob pressão reduzida a $40^{\circ} \mathrm{C}$ em evaporador rotatório, em banho-maria, sendo posteriormente congelado e liofilizado.

A FSA liofilizada foi diluída com água destilada e tratada com resinas catiônica e aniônica por cinco minutos em agitador e, em seguida, foi filtrada e liofilizada. À FSA purificada foi adicionado $1 \mathrm{~mL}$ de água destilada para as análises quantitativas de glucose, frutose e sorbitol por cromatografia líquida de alta eficiência (HPLC). Utilizaram-se soluções-padrão de glucose, frutose e sorbitol (Sigma Chemical Co.; St. Louis, EUA) para construção de curva-padrão nas concentrações de 0,1 a $2,0 \mathrm{mg} \mathrm{mL}^{-1}$. Os valores obtidos foram expressos em miligrama de carboidrato específico por grama de matéria seca da amostra.

O delineamento experimental adotado foi de parcelas subdivididas no tempo, com o fator principal arranjado em blocos casualizados. O fator principal estudado foi o tratamento com frio com dois níveis e as subparcelas foram representadas pelas datas de coleta de ramos com sete níveis, utilizando-se três repetições. A comparação entre médias de tratamentos foi feita pelo teste Tukey ao nível de significância de 5\%.

\section{RESULTADOS E DISCUSSÃO}

As gemas de dois anos que não receberam tratamento com frio suplementar apresentaram evolução significativa no conteúdo de glucose e frutose durante o período estudado. Já o conteúdo de sorbitol apresentou oscilações ao longo dos meses, mas, no final de agosto, encontrava-se em níveis mais elevados que em abril (Tabela 1). Sendo o sorbitol um importante produto fotossintético de armazenamento, transporte e de elevada capacidade de regulação osmótica e proteção celular (LOESCHER \& EVERARD, 1996), em especial em plantas da família Rosaceae como a pereira (HERTER et al., 2001), a natureza não redutora da molécula (SALISBURY \& ROSS, 1992) permite que esta última desempenhe mais facilmente o papel de transporte nos tecidos que a glucose e a frutose. Assim, oscilações de seu conteúdo ocorrem primeiramente em relação a outros carboidratos. Segundo CARVALHO (2001), as gemas de dois anos de idade de macieira apresentaram redução do nível de carboidratos solúveis totais até o mês de junho, com pequenas oscilações nos meses seguintes, até antes da brotação a campo. Assim, o aumento dos monossacarídeos, o da glucose, da frutose e do sorbitol encontrado sugere que outros mono ou oligossacarídeos podem ser degradados e exportados da gema. Variações do conteúdo de oligossacarídeos na dormência mais intensa já foram encontradas em gemas de pessegueiro, pois MARQUAT et al. (1999) concluíram que ocorreu aumento do conteúdo de estaquiose e rafinose, derivados da sacarose.

A morfologia interna de grande parte de gemas de dois anos mostra a existência de um eixo caulinar perfeitamente formado e ligado ao ramo (CARVALHO \& ZANETTE, 2005). Esta perfeita vascularização no interior de gemas mais velhas da macieira pode tornar mais dinâmico o transporte de moléculas, em especial as de natureza não redutora, tanto da gema para os tecidos adjacentes quanto no sentido oposto, de acordo com a necessidade fisiológica da planta. Como durante a dormência de caducifólias não há tecidos fotossintetizantes eficientes, além da gema e dos ramos adjacentes serem drenos de fotoassimilados, o acúmulo de glucose, frutose e sorbitol acontece pela translocação de tecidos adjacentes, não havendo impedimentos físicos ou fisiológicos que a impossibilitem. O transporte nestes tecidos acontece a distâncias muito curtas e pode ocorrer via simplasto ou apoplasto (THORPE \& MINCHIN, 1996).

O tratamento com frio suplementar acarretou em acúmulo de glucose e frutose nas gemas em todo o período estudado. O conteúdo de sorbitol apresentou também elevação em quase todas os meses, exceto no início de maio, quando houve redução em comparação com as gemas que não receberam frio, e no início de agosto, quando os níveis permaneceram iguais nas gemas que receberam ou não frio suplementar (Tabela 1). Segundo CARVALHO \& ZANETTE (2004b), a endodormência mais intensa de gemas de dois anos de macieira "Imperial Gala” cultivada na região de Porto Amazonas, Paraná, estendeu-se do final de maio até o início de agosto, não havendo um pico bem definido. Dessa forma, o tratamento com frio suplementar provocou acúmulo significativo dos três carboidratos nas gemas tanto na endodormência, mais profunda 
Tabela 1 - Conteúdo de glucose, frutose e sorbitol em gemas e ramos adjacentes de dois anos de idade de macieira da cultivar Imperial Gala que receberam ou não tratamento com 1440 horas de frio suplementar de 4 a $7^{\circ} \mathrm{C}$.

\begin{tabular}{|c|c|c|c|c|c|c|c|c|c|c|c|c|}
\hline \multirow{4}{*}{$\begin{array}{l}\text { Datas de } \\
\text { avaliação }\end{array}$} & \multicolumn{12}{|c|}{ Conteúdo do carboidrato ( $\mathrm{mg} \mathrm{g}^{-1}$ de matéria seca) em função do tratamento com frio } \\
\hline & \multicolumn{4}{|c|}{ Glucose } & \multicolumn{4}{|c|}{ Frutose } & \multicolumn{4}{|c|}{ Sorbitol } \\
\hline & \multicolumn{2}{|c|}{ Com } & \multicolumn{2}{|c|}{ Sem } & \multicolumn{2}{|c|}{ Com } & \multicolumn{2}{|c|}{ Sem } & \multicolumn{2}{|c|}{ Com } & \multicolumn{2}{|c|}{ Sem } \\
\hline & & & & & & & & & & & & \\
\hline $19 / 04$ & 15,87 & Ae & 2,24 & $\mathrm{Bf}$ & 17,61 & $\mathrm{Ae}$ & 2,62 & $\mathrm{Be}$ & 39,91 & $\mathrm{Ab}$ & 29,38 & $\mathrm{Bd}$ \\
\hline $10 / 05$ & 17,35 & Ad & 6,92 & $\mathrm{Be}$ & 18,31 & Ad & 6,67 & $\mathrm{Bd}$ & 25,09 & $\mathrm{Bd}$ & 35,62 & $\mathrm{Ab}$ \\
\hline $31 / 05$ & 19,07 & $\mathrm{Aa}$ & 7,72 & $\mathrm{Bd}$ & 19,32 & $\mathrm{Ab}$ & 7,15 & $\mathrm{Bc}$ & 36,54 & Ac & 30,42 & $\mathrm{Bd}$ \\
\hline $21 / 06$ & 15,22 & Af & 7,59 & $\mathrm{Bd}$ & 16,92 & Af & 8,09 & $\mathrm{Bb}$ & 35,51 & Ac & 25,16 & $\mathrm{Be}$ \\
\hline $12 / 07$ & 17,81 & Ac & 8,72 & $\mathrm{Bc}$ & 18,91 & Ac & 9,74 & $\mathrm{Ba}$ & 45,78 & $\mathrm{Aa}$ & 33,34 & $\mathrm{Bc}$ \\
\hline 02/08 & 18,39 & $\mathrm{Ab}$ & 9,43 & $\mathrm{Bb}$ & 20,16 & Аа & 9,67 & $\mathrm{Ba}$ & 39,41 & $\mathrm{Ab}$ & 39,50 & $\mathrm{Aa}$ \\
\hline 23/08 & 15,37 & Af & 10,08 & $\mathrm{Ba}$ & 15,88 & $\mathrm{Ag}$ & 9,86 & Ba & 40,45 & $\mathrm{Ab}$ & 34,60 & Bbc \\
\hline CV (\%) & 1,09 & & & & 0,96 & & & & 1,56 & & & \\
\hline \multicolumn{13}{|l|}{ Ramos } \\
\hline $19 / 04$ & 9,86 & Ac & 0,69 & $\mathrm{Bf}$ & 9,17 & $\mathrm{Ae}$ & 0,78 & $\mathrm{Bf}$ & 23,84 & Ac & 17,37 & $\mathrm{Be}$ \\
\hline $10 / 05$ & 11,13 & $\mathrm{Ab}$ & 4,31 & $\mathrm{Be}$ & 10,90 & Ac & 4,39 & $\mathrm{Be}$ & 21,03 & Ad & 19,81 & Bcd \\
\hline $31 / 05$ & 12,81 & $\mathrm{Aa}$ & 9,60 & $\mathrm{Bc}$ & 15,77 & $\mathrm{Aa}$ & 8,81 & $\mathrm{Bc}$ & 28,36 & $\mathrm{Aa}$ & 21,32 & $\mathrm{Bb}$ \\
\hline $21 / 06$ & 11,00 & $\mathrm{Ab}$ & 8,58 & $\mathrm{Bd}$ & 12,03 & $\mathrm{Ab}$ & 8,46 & $\mathrm{Bc}$ & 25,95 & $\mathrm{Ab}$ & 19,02 & $\mathrm{Bd}$ \\
\hline $12 / 07$ & 6,46 & $\mathrm{Be}$ & 11,11 & $\mathrm{Ab}$ & 7,72 & $\mathrm{Bf}$ & 11,69 & $\mathrm{Ab}$ & 18,67 & $\mathrm{Be}$ & 22,93 & $\mathrm{Aa}$ \\
\hline 02/08 & 11,25 & $\mathrm{Bb}$ & 12,19 & $\mathrm{Aa}$ & 12,36 & $\mathrm{Bb}$ & 13,36 & $\mathrm{Aa}$ & 26,43 & $\mathrm{Ab}$ & 20,51 & Bbc \\
\hline 23/08 & 8,92 & Ad & 8,06 & $\mathrm{Bd}$ & 10,13 & Ad & 7,67 & $\mathrm{Bd}$ & 25,60 & $\mathrm{Bb}$ & 20,23 & Abc \\
\hline CV (\%) & 2,53 & & & & 1,61 & & & & 2,01 & & & \\
\hline
\end{tabular}

*Médias seguidas por letras distintas, maiúsculas nas linhas e minúsculas nas colunas, dentro de cada carboidrato, diferem entre si pelo teste Tukey em nível de 5 \% de significância.

quanto na saída da endodormência, em agosto. Com a ocorrência de baixas temperaturas, normalmente o conteúdo de sorbitol aumenta na macieira (LOESCHER \& EVERARD, 1996). Porém, após o tratamento com frio, realizado precocemente em maio, a sua característica de acumulação foi alterada. Contudo, estas variações são específicas para as espécies frutíferas, pois HERTER et al. (2002) encontraram alterações do conteúdo de sorbitol em gemas de pereiras causada pela flutuação térmica, mas o fato não ocorreu para a glucose e a frutose.

Com a evolução da dormência, a relação entre glucose, frutose e sorbitol nas gemas sem frio suplementar se modificou de 1:1:13, na entrada em endodormência em abril, para, em média, 1:1:4 durante a endodormência mais profunda do fim de maio ao início de agosto, e para 1:1:3,5 ao final da endodormência em agosto, indicando uma dinâmica semelhante de alteração no conteúdo de glucose e frutose ao longo dos meses e a diminuição das suas diferenças em relação ao sorbitol.

Nas porções de ramos adjacentes às gemas de dois anos de idade, o conteúdo de glucose e frutose aumentou a partir de abril, com pequenas oscilações em maio e junho, até o final da dormência no início de agosto e, em seguida, diminuiu com e sem tratamento com frio suplementar (Tabela 1). A queda do conteúdo destes dois monossacarídeos pode estar relacionada à exportação dos mesmos às gemas ou à sua utilização pela respiração celular na fase final da dormência, na qual ocorre aumento da atividade metabólica nos tecidos como preparação para um novo fluxo de crescimento. Segundo HERTER et al. (2001), a translocação de carboidratos para as gemas pode ser indicação do término da endodormência.

O conteúdo de sorbitol nos ramos sem tratamento com frio aumentou de abril até julho, com oscilações no mês de junho e, em seguida, foi reduzido, mas permaneceu em valores mais elevados que os encontrados em abril. Este decréscimo de sorbitol no final da endodormência pode estar relacionado, em especial, com sua exportação às gemas, visando à manutenção de um fluxo constante em direção à gema que em breve iniciará o crescimento, pois, neste período, no qual a endodormência ainda é intensa (CARVALHO \& ZANETTE, 2004b), a atividade metabólica é reduzida (PETRI et al., 1996). A antecipação desta exportação do sorbitol (início de agosto) em 
relação à de glucose e frutose (final de agosto) determina que as oscilações de seu conteúdo no final da endodormência ocorram, primeiramente, em relação a outros carboidratos.

O tratamento com frio suplementar promoveu o acúmulo de glucose e frutose nos ramos coletados até junho. Já em julho e início de agosto, o frio proporcionou a sua redução. Dinâmica semelhante ocorreu para o sorbitol e, dessa forma, pode-se considerar que a ocorrência do frio precoce antecipou o acúmulo de carboidratos nos ramos de dois anos, fato que aconteceria no campo apenas na saída da endodormência.

Com a evolução da dormência, a relação de glucose, frutose e sorbitol nos ramos adjacentes às gemas de dois anos que não receberam frio suplementar modificou-se de 1:1:25 na entrada em dormência em abril para, em média, 1:1:2 na dormência mais profunda do final de maio a início de agosto e para 1:1:3 ao final da dormência em agosto. As modificações dessas relações em ramos durante a dormência tiveram uma dinâmica semelhante às ocorridas nas gemas.

\section{CONCLUSÃO}

Há acúmulo de glucose e frutose em gemas de macieira de abril a agosto, e este aumento é estimulado pelo tratamento com 1.440 horas de frio, representando um indicativo de término da dormência. O conteúdo de glucose e frutose nos ramos adjacentes às gemas eleva-se de abril ao início de agosto, com posterior queda no final de agosto, e o tratamento com frio antecipa esta dinâmica. O conteúdo de sorbitol em gemas e ramos de macieira oscila de abril a agosto e sua dinâmica é alterada pelo frio.

\section{AGRADECIMENTOS}

Aos professores Dra. Juliana Maurer-Menestrina e Dr. Luis Pereira Ramos, pela orientação nas análises.

\section{REFERÊNCIAS}

CARVALHO, R.I.N. Dinâmica da dormência e do conteúdo de carboidratos e proteínas em gemas vegetativas e ramos de um e dois anos de macieira com ou sem frio suplementar. 2001. 134f. Tese (Doutorado em Produção Vegetal) - Curso de Pós-graduação em Produção Vegetal, Setor de Ciências Agrárias, Universidade Federal do Paraná.

CARVALHO, R.I.N.; ZANETTE, F. Conteúdo de carboidratos em gemas e ramos de macieira durante o outono e inverno em região de baixa ocorrência de frio. Revista Brasileira de Fruticultura, Jaboticabal, v.26, n.2, p.202-205, 2004a.
CARVALHO, R.I.N.; ZANETTE, F. Dinâmica da dormência de gemas de dois anos de macieira 'Imperial Gala' em região de baixa ocorrência de frio. Revista Brasileira de Fruticultura, Jaboticabal, v.26, n.3, p.392-394, 2004b.

CARVALHO, R.I.N.; ZANETTE, F. Morfologia de gemas dormentes com um ano e dois anos de macieiras cultivadas em regiões com insuficiência de frio hibernal. Revista Agropecuária Catarinense, Florianópolis, v.18, n.2, p.6872, 2005.

CRABBÉ, J.; BARNOLA, P.A. New conceptual approach to bud dormancy in woody plants. In: LANG, G.A. (Ed). Plant dormancy: physiology, biochemistry and molecular biology. New York: CAB International, 1996. p.83-113.

EREZ, A. Bud dormancy: a suggestion for the control mechanism and its evolution. In: VIÉMONT, J.-D.; CRABBÉ, J. (Ed). Dormancy in plants: From whole plant behaviour to cellular control. Cambridge: University, 2000. p.23-33.

FLORE, J.A.; LAYNE, D.R. Prunus. In: ZAMSKI, E.; SCHAFFER, A.A. Photoassimilate distribution in plants and crops: source-sink relationships. New York: Marcel Dekker, 1996. p.825-849.

GAUDILLÈRE, J.P. et al. Vigour and non-structural carbohydrates in young prune trees. Scientia Horticulturae, Amsterdam, v.51, p.197-211, 1992.

HERTER, F. et al. Níveis de carboidratos em tecidos de pereiras cv. Nijisseiki em duas épocas que antecedem o florescimento. In: CONGRESSO BRASILEIRO DE FISIOLOGIA VEGETAL, 8., 2001, Ilhéus, BA, Brasil. Anais... Ilhéus: SBFV, 2001. 1 CD.

HERTER, F. et al. Concentração de carboidratos em gemas florais de pereira cv. Nijisseiki submetidas à flutuação térmica durante o período de dormência. In: CONGRESSO BRASILEIRO DE FRUTICULTURA, 17., 2002, Belém, PA, Brasil. Anais... Belém: SBF, 2002. 1 CD.

LANG, G.A. et al. Endo-, para- and ecodormancy: physiological terminology and classification for dormancy research. Hortscience, Alexandria, v.22, p.371-178, 1987.

LARCHER, W. Ecofisiologia vegetal. São Carlos: RiMa Artes e textos, 2000. 531p.

LEITE, G.B. et al. Evolução fisiológica e bioquímica de gemas vegetativas de pessegueiro durante o período de repouso hibernal. In: CONGRESSO BRASILEIRO DE FRUTICULTURA, 18., 2004, Florianópolis, SC, Brasil. Anais... Florianópolis: SBF, 2004. 1 CD.

LOESCHER, W.H.; EVERARD, J.D. Sugar alcohol metabolism in sinks and sources. In: ZAMSKI, E.; SCHAFFER, A.A. Photoassimilate distribution in plants and crops: sourcesink relationships. New York: Marcel Dekker, 1996. p.185207.

MARQUAT, C. et al. Dormancy in vegetative buds of peach: relation between carbohydrate absorption potentials and carbohydrate concentration in the bud during dormancy and its release. Scientia Horticulturae, Amsterdam, v.79, p.151162, 1999. 
PETRI, J.L. et al. Dormência e indução da brotação de fruteiras de clima temperado. Florianópolis: EPAGRI, 1996. 110p. (Boletim Técnico, 75).

QUICK, W.P.; SCHAFFER, A.A. Sucrose metabolism in sources and sinks. In: ZAMSKI, E.; SCHAFFER, A.A. Photoassimilate distribution in plants and crops: source-sink relationships. New York: Marcel Dekker, 1996. p.115-156.

SALISBURY, F.B.; ROSS C.W. Plant physiology. Califórnia: Wadsworth, 1992. 682p.
SHALTOUT, A.D.; UNRATH, C.R. Effect of some growth regulators and nutritional compounds as substitutes for chilling of Delicious apple leaf and flower buds. Journal of the American Society for Horticultural Science, Alexandria, v.108, n.6, p.898-901, 1983.

THORPE, M.R.; MINCHIN, P.E.H. Mechanisms of long- and short-distance transport from sources to sinks. In: ZAMSKI, E.; SCHAfFeR, A.A. Photoassimilate distribution in plants and crops: source-sink relationships. New York: Marcel Dekker, 1996. p.261-282. 